\title{
Study of Patient's Satisfaction at Urology Ward of Shahid Beheshti Hospital, Hamadan University of Medical Sciences in the Second Half of 2018
}

\section{Seyed Mohammad Zolhavarieh ${ }^{1}{ }^{(\mathbb{D})}$, Mahmoud Rezaei $^{*{ }^{* 1}}{ }^{(\mathbb{D})}$, Nasim Karimi $^{2}{ }^{(\mathbb{D})}$, Ronak Hamzehei $^{3}$, Mojgan Zeraatkarmoghaddam ${ }^{4}$}

1. Assistant Professor, Anesthesia Department, Clinical Research Development Unit of Shahid Beheshti Hospital, Hamadan University of Medical Sciences, Hamadan, Iran

2. MSc in Biostatistics, Clinical Research Development Unit of Beheshti Hospital, Hamadan University of Medical Sciences, Hamadan, Iran

3. MSc in MLIS, Clinical Research Development Unit of Beheshti Hospital, Hamadan University of Medical Sciences, Hamadan, Iran

4. BS in Nursing, Clinical Research Development Unit of Beheshti Hospital, Hamadan University of Medical Sciences, Hamadan, Iran

\section{Article Information}

Article History

Received: $\quad 2019 / 08 / 07$

Accepted: $\quad$ 2019/09/15

Available Online: 2019/09/16

JUR 2019; 3(1):19-27

DOI: 10.30699/jru.3.1.19

Use your device to scan and read the article online

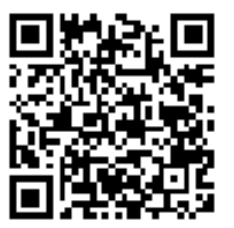

Corresponding Author

Mahmoud Rezaei

Assistant Professor, Anesthesia Department, Clinical Research Development Unit of Shahid Beheshti hospital, Hamadan University of Medical sciences, Hamadan, Iran

Tel: $081-38380092$

Email:

mrezaei1961@yahoo.com

\section{Abstract}

Background \& Objective: Satisfaction is one of the health aspects of human. Without attention to people's satisfaction in the health services, the health system act contrary to its mission. The aim of this study is to evaluate the patient's satisfaction in the urology ward at Shahid Beheshti Hospital in Hamadan University of Medical Sciences in second half of 2018, for investigating the strengths and weaknesses with provide guidance and better quality treatments.

Methods: In this cross-sectional study, 170 hospitalized patients in the Urology ward in shahid beheshti hospital during the second half of 2018 were studied. Data were analyzed with SPSS 16.

Results: The results showed that the average satisfaction rate of all services was $77.25 \%$. However, the highest satisfaction with nursing services is 80.8 and the lowest satisfaction with public services is 72.6 . There were significant relationships between demographic variables such as age, sex and level of education with total satisfaction.

Conclusions: From the viewpoint of patients at Shahid Beheshti Hospital in Hamadan, the total services and facilities that report, are to be desirable.

Keywords: Patient's Satisfaction, Medical and Nursing Services

How to cite this article:

Zolhavarieh S M, Rezaei M, Karimi N, Hamzehei R, Zeraatkarmoghaddam M. Study of patient〉s satisfaction at urology ward, of Shahid Beheshti hospital, Hamadan University of Medical sciences in the second half of 2018. J Res Urol. 2019; 3 (1) :19-27 


$$
\begin{aligned}
& \text { بررسى رضايتمندى بيماران بسترى در بخش ارولوزى بيمارستان شهيد بهشتى }
\end{aligned}
$$

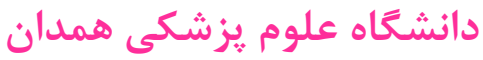

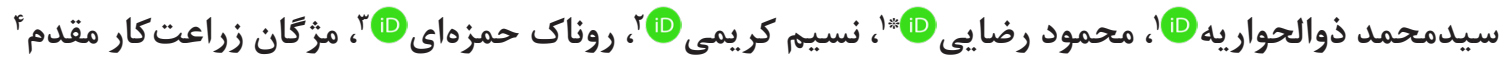

ا. استاديار، كروه بيهوشى، واحد توسعه تحقيقات بالينى بيمارستان شهيد بهشتى، دانشكاه علوم يزشكى همدان، همدان، ايران

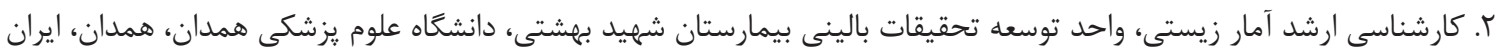

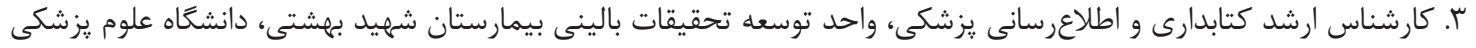
همدان، همدان، ايران f. كارشناسى يرستارى، واحد توسعه تحقيقات بالينى بيمارستان شهيد بهشتى، دانشعاه علوم يزشكى همدان، همدان، ايران

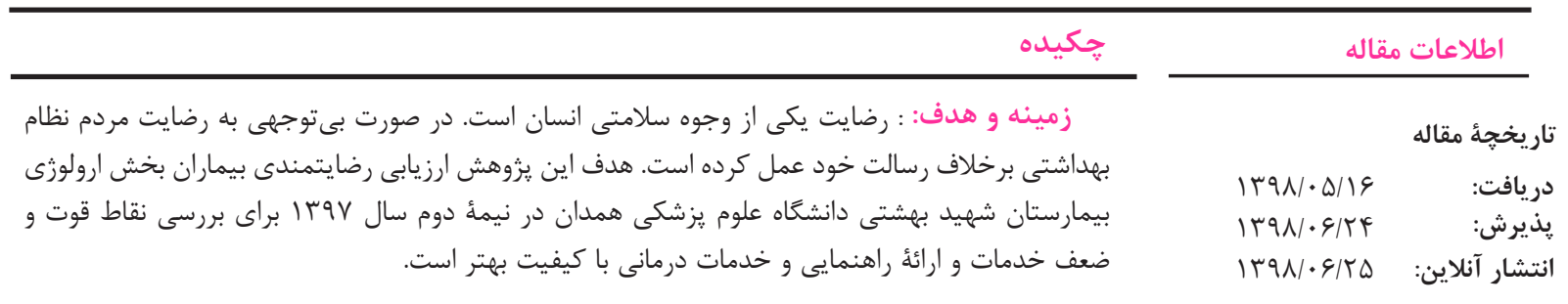

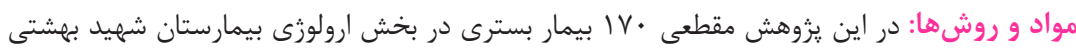

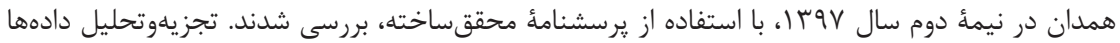

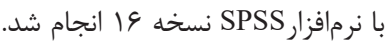

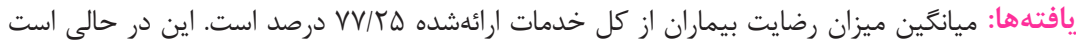

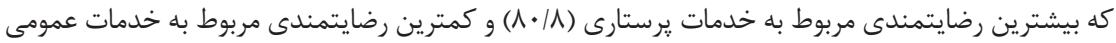
(VY/9) معنى دارى مشاهده شد.

نتيجهَّيرى: از ديدكًاه بيماران بيمارستان شهيد بهشتى همدان همأ خدمات و تسهيلاتى كه ارائه مىشود در حد مطلوب است. وازوهاى كليدى: رضايت بيمار، خدمات يزشكى و يرستارى

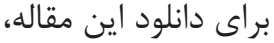

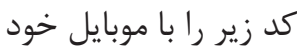
اسكن كنيد.

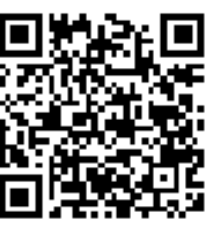

نويسنده مسئول: محمود رضايى، استاديار، گروه بيهوشى، واحد توسعه تحقيقات بالينى بيمارستان شهيد بهشتى، دانشعاه علوم يزشكى همدان، همدان، ايران تلفن : mrezaei1961@yahoo.com 


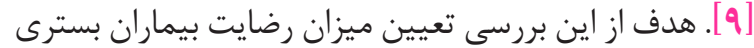

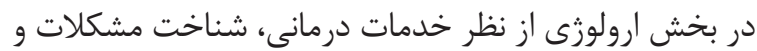

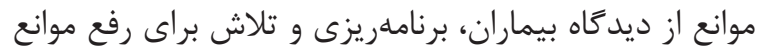

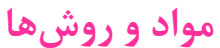

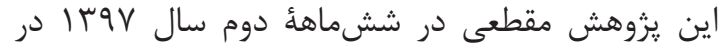

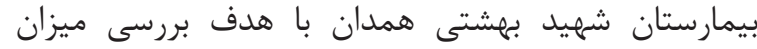

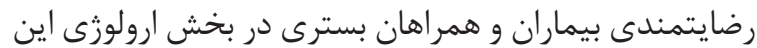

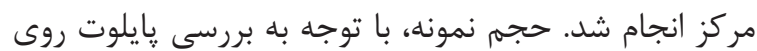

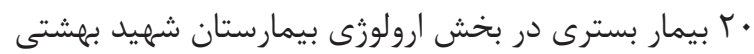

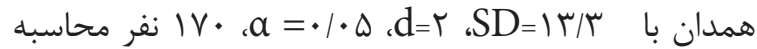

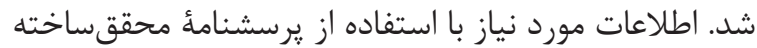

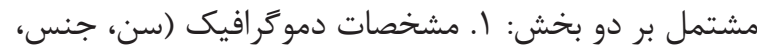

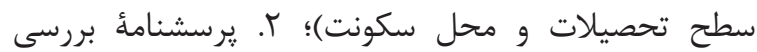

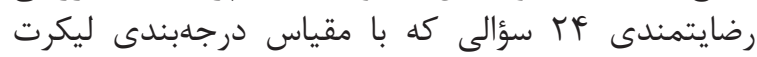

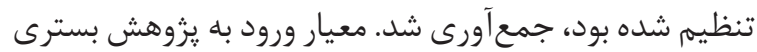

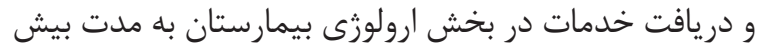

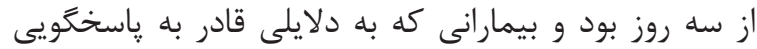

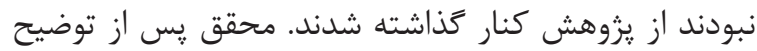

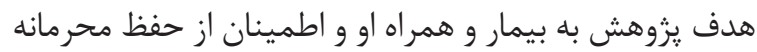

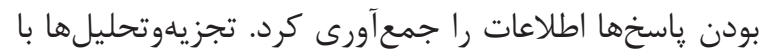

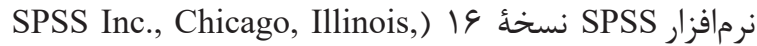

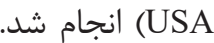

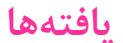

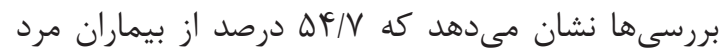

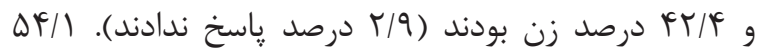

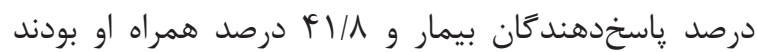

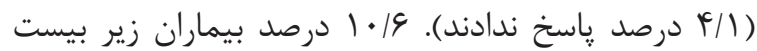

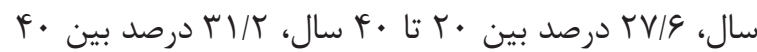

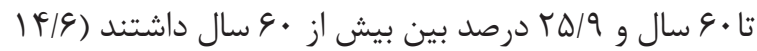

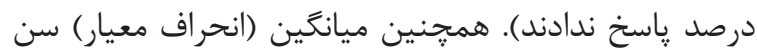

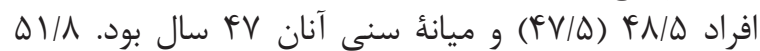

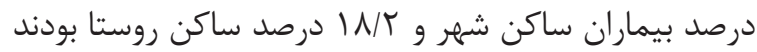

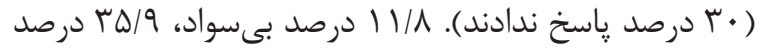

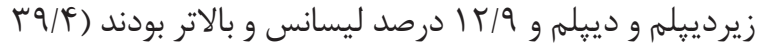

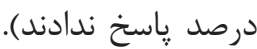

سلامتى حق انسان است و هر فرد حق مطالبئ آن را دارده دارد.

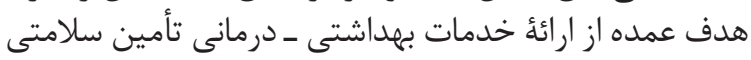

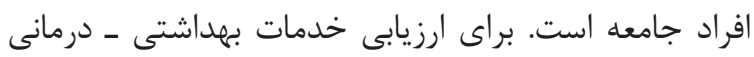

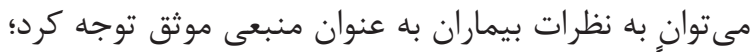

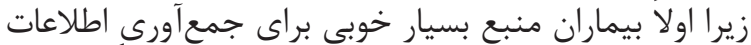

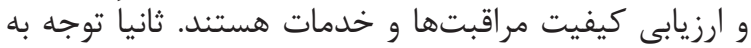

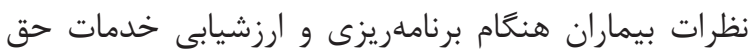

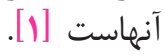

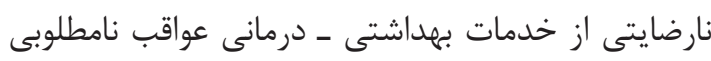

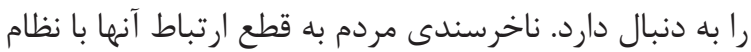

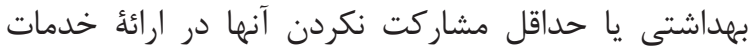

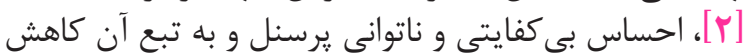

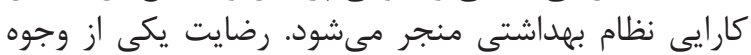

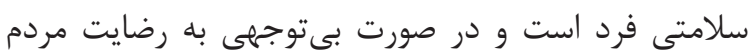

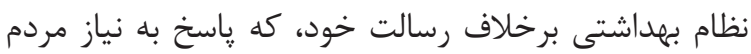

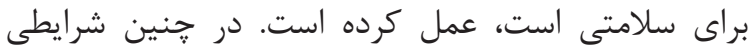

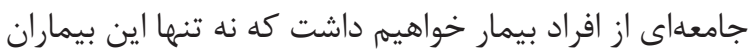

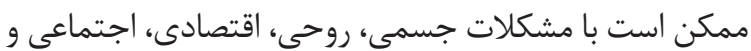

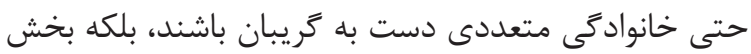

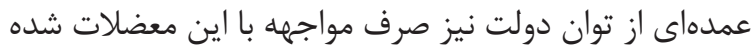

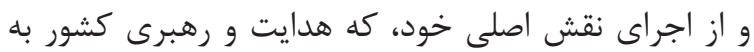

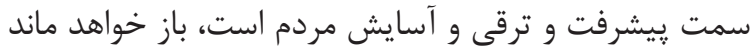

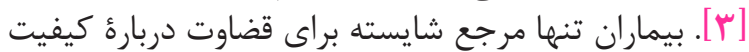

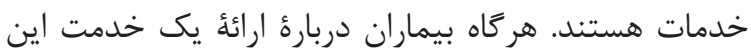

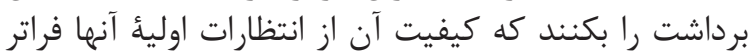

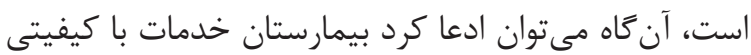

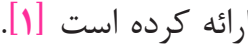

مراقبت سلامت در ارتقاى سطح سلامت بيماران، روند

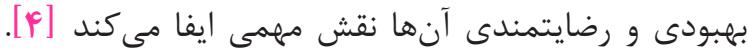

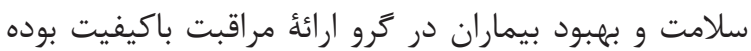

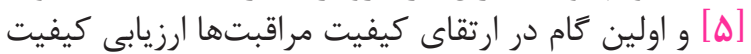

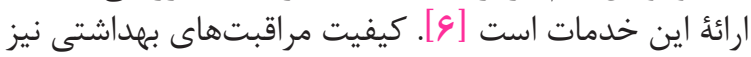

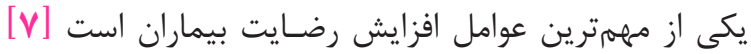

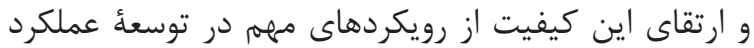

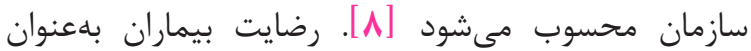

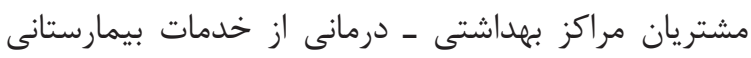

جدول ا. بررسى ميانَين، انحراف معيار ميزان رضايتمندى از بخش ارولوزى

\begin{tabular}{|c|c|c|c|}
\hline ميانكين از . & انحراف معيار & ميانكَين & ابعاد \\
\hline$\Lambda \cdot / \Lambda$ & $9 / V$ & $\varphi \cdot / \varphi$ & خدمات يرستارى \\
\hline$\wedge$. & $r / V$ & 19 & خدمات يزشكى \\
\hline$V T / G$ & $\Lambda / 4$ & $r g / r$ & خدمات عمومى \\
\hline$V V / T$ & $\mid F / 9$ & $9 T / V$ & رضايتمندى كل \\
\hline
\end{tabular}

rI 


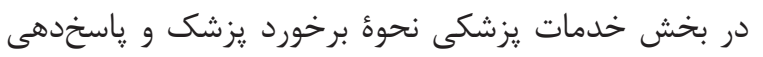

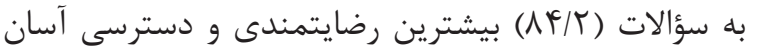

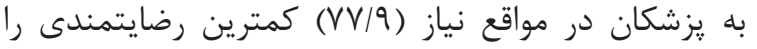

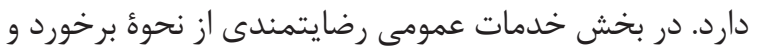

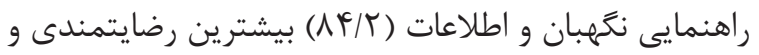

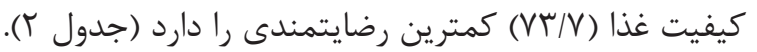

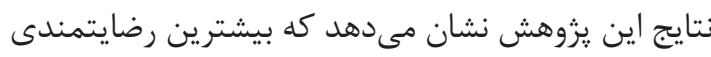

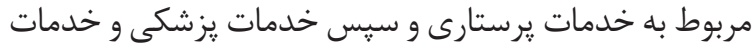

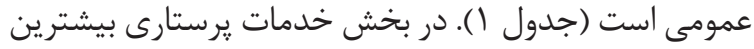

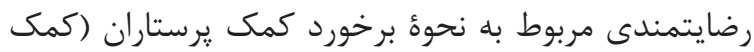

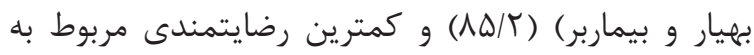

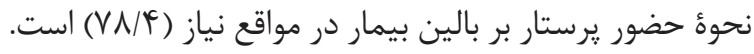

\section{جدول r. بررسى ميانگين سوالا ت مربوط به ابعاد مختلف رضايتمندى از بخش ارولوزى}

$$
\text { ميانگين از . }
$$

$N / \cdot r$

\begin{tabular}{|c|c|c|}
\hline$\Lambda \cdot / \Lambda$ & نحوه برخورد يرستاران بخش و ياسخ به سوالات شما & r \\
\hline$\wedge 1$ & ميزان مهارت يرستار در انجام امور & r \\
\hline$\Lambda \cdot / \Lambda$ & نحوه آموزش يرستاران در خصوص بيمارى، درمان، مراقبت، دارو و ... & r \\
\hline$\wedge \mu / \Lambda$ & استفاده از يرسنل همكن در انجام اقدامات درمانى & $\Delta$ \\
\hline$\Lambda \cdot / 4$ & محيط آرام و بى سرو صدا توسط يرستاران & द \\
\hline$V N / \uparrow$ & نحوه حضور يرستار بر بالين بيمار در مواقع مورد نياز & v \\
\hline$\Lambda F / r$ & رعايت مسائل شرعى و حفظ حريم شخصى در انجام خدمات يزشكى، مراقبتى، ياراكلينيكى & $\wedge$ \\
\hline$\Lambda \Delta / r$ & نحوه برخورد كمك يرستاران (كمك بهيار و بيمار بر) & 9 \\
\hline$\Lambda \mu / 9$ & رضايت از خدمات كمك يرستاران & $1 \cdot$ \\
\hline$\Lambda F / r$ & برخورد يزشكان و ياسخ به سوالات شما & 11 \\
\hline$\Lambda 1 / \Lambda$ & اختصاص وقت كافى توسط يزشكان جهت ويزيت و معاينه و ارائه اطلاعات در مورد برنامه درمانى & ir \\
\hline $\mathrm{V} / \mathrm{A}$ & دسترسى آسان به يزشكان در مواقع مورد نياز & ir \\
\hline$\Lambda \cdot / \Lambda$ & ارائه اطلاعات و آكاهى لازم در مورد بيمارى و نحوه مراقبت & if \\
\hline$\Lambda F / r$ & طرز برخورد و راهنمايى نكهبانى و اطلاعات & 10 \\
\hline$\vee 9 / \wedge$ & وضعيت بهداشت و نظافت بخش و سرويس هاى بهداشتى & 19 \\
\hline ve & امكانات رفاهى، امكانات همراه(صندلى، غذا و...) و وضعيت آسانسور & IV \\
\hline$V \Delta / r$ & سكوت و آرامش محيط بيمارستان و بخش & 11 \\
\hline$V M / 9$ & كيفيت غذاى سرو شده & 19 \\
\hline vel9 & 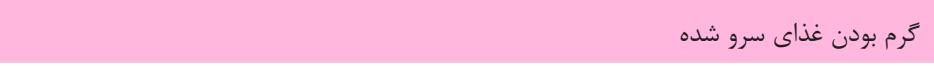 & r. \\
\hline$\vee \& / 9$ & مناسب بودن زمان توزيع غذا & r) \\
\hline$V V / T^{c}$ & ظروف سرو غذا & rt \\
\hline v & تنوع غذائى در وعده هاى غذائى & r \\
\hline$\Lambda \cdot / \Lambda$ & روزها و ساعات ملاقات & re \\
\hline
\end{tabular}

سوالات

$$
\text { | معرفى يرستار به بيمار و شناسايى يرستار مربوطه توسط بيمار }
$$




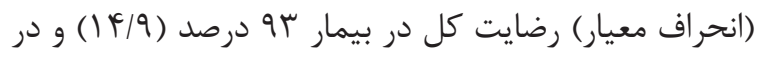

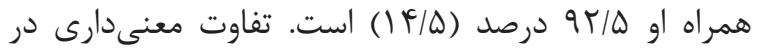

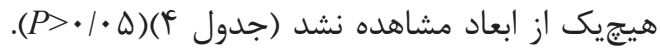

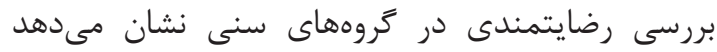

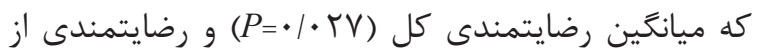

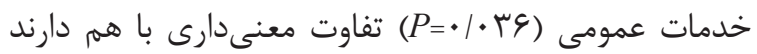

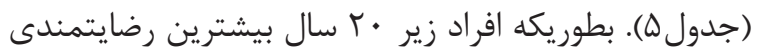

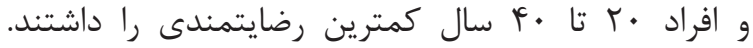

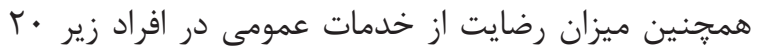

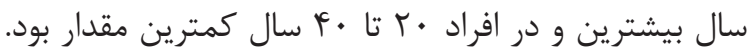

ميانكَين رضايتمندى از خدمات يرستارى در مردان و زنان

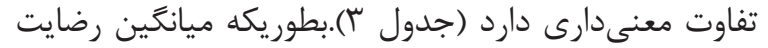

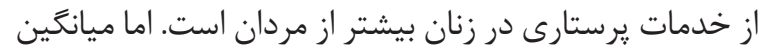

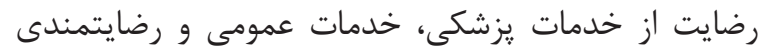

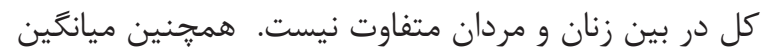

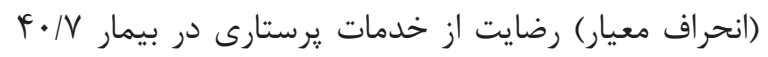

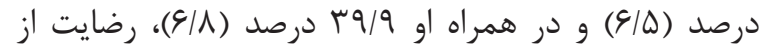

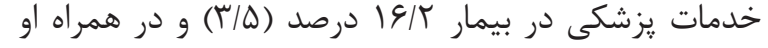

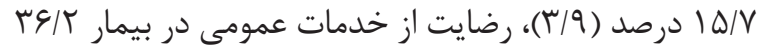

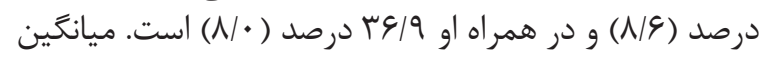

جدول r. بررسى رضايتمندى و ابعاد آن بر حسب جنسيت در بيماران بسترى در بخش ارولوزى

\begin{tabular}{|c|c|c|c|c|c|}
\hline$P$ & ميانكين از . & انحراف معيار & ميانكين & طبقات & ابعاد \\
\hline \multirow{2}{*}{$.1 \cdot 11$} & vı & v & rq & مرد & \multirow[t]{2}{*}{ خدمات يرستارى } \\
\hline & $\wedge r / l$ & $\Delta / V$ & $|f| / Q$ & زن & \\
\hline \multirow{2}{*}{.$/ 114$} & $V V / F$ & $\mid r / V$ & $1 \Delta / \Delta$ & مرد & \multirow{2}{*}{ خدمات يزشكى } \\
\hline & NT & $r / V$ & $\mid \varepsilon / F$ & زن & \\
\hline \multirow{2}{*}{$\cdot 11199$} & $V \Psi / I$ & $N / T$ & re/4 & مرد & \multirow{2}{*}{ خدمات عمومى } \\
\hline & $V T / A$ & $\Lambda / \Delta$ & $r \varepsilon / \uparrow$ & زن & \\
\hline \multirow{2}{*}{.$/ 14}$. & $V \Delta / q$ & $\mid F / F$ & 91 & مرد & \multirow{2}{*}{ رضايتمندى كل } \\
\hline & VA & if & $q F / \%$ & زن & \\
\hline
\end{tabular}

جدول F: بر رسى رضايتمندى و ابعاد آن بر حسب پاسخ دهنده در بيماران بسترى در بخش ارولوزى

\begin{tabular}{|c|c|c|c|c|c|}
\hline$P$ & ميانگين از · & انحراف معيار & ميانگين & طبقات & 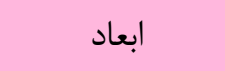 \\
\hline \multirow{2}{*}{$\cdot|\& \&|$} & $\Lambda 1 / r$ & $9 / 0$ & $f \cdot / V$ & بيمار & \multirow{2}{*}{ خدمات يرستارى } \\
\hline & $\vee १ / \wedge$ & $4 / \Lambda$ & एq/q & همراه بيمار & \\
\hline \multirow{2}{*}{$\cdot / F \cdot \Delta$} & $11 /$. & T/Q & $19 / \pi$ & بيمار & \multirow{2}{*}{ خدمات يزشكى } \\
\hline & VA/G & $r / q$ & $I D / V$ & همراه بيمار & \\
\hline \multirow{2}{*}{ - IDFT } & $V T / T$ & $\Lambda / 9$ & rq/T & بيمار & \multirow{2}{*}{ خدمات عمومى } \\
\hline & VT/A & $\Lambda / \cdot$ & rq/q & همراه بيمار & \\
\hline \multirow{2}{*}{ - IAFD } & $V V / \Delta$ & $19 / 9$ & . & بيمار & \multirow{2}{*}{ رضايتمندى كل } \\
\hline & $V V / I$. & $\mid F / Q$ & $9 r / 0$ & همراه بيمار & \\
\hline
\end{tabular}

rr 
جدول هـ. بررسى رضايتمندى و ابعاد آن بر حسب سن بيماران بسترى در بخش ارولوزى

\begin{tabular}{|c|c|c|c|c|c|}
\hline$P$ & ميانكَين از . . & انحر اف معيار & ميانكَين & طبقات & ابعاد \\
\hline \multirow{4}{*}{ 每 } & $\wedge \Delta / 1$ & $\Delta / 9$ & FT/G & زير • † سال & \multirow{4}{*}{ خدمات برستارى } \\
\hline & $V A / \Lambda$ & $\mathrm{V} / \mathrm{\Lambda}$ & $r q / 4$ & 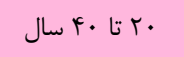 & \\
\hline & $11 / 4$ & $\Delta / 1$ & $r \cdot / v$ & . Fا •ع سال & \\
\hline & $11 / 9$ & 911 & $4 \cdot 19$ & بيشتر از •و سال & \\
\hline \multirow{4}{*}{. /Ir } & $\Lambda N / \Lambda$ & $r / 9$ & IV/A & زير • r سال & \multirow{4}{*}{ خدمات يزشكى } \\
\hline & $V V / f$ & $r / 9$ & $1 Q / \Delta$ & 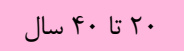 & \\
\hline & VA/V & $r / \Delta$ & $1 Q / V$ & 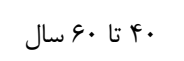 & \\
\hline & $11 / 9$ & f & $19 / 4$ & بيشتر از •و سال & \\
\hline \multirow{4}{*}{ 每. } & vı & $\Lambda / V$ & rq & زير •r سال & \multirow{4}{*}{ خدمات عمومى } \\
\hline & $9 V / D$ & $9 / 4$ & 贾 & 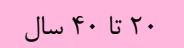 & \\
\hline & VQ & $V / f^{e}$ & $r V / \Delta$ & • F تا •q سال & \\
\hline & $V F / \Lambda$ & 919 & $r V / F$ & بيشتر از •و سال & \\
\hline \multirow{4}{*}{.$/ \cdot t r$} & $\Lambda r / \Lambda$ & $I T / V$ & $99 / \Gamma$ & زير •r سال & \multirow{4}{*}{ رضايتمندى كل } \\
\hline & $V r / 9$ & $9 / 19$ & $1 \mathrm{~N} / 9$ & 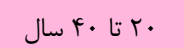 & \\
\hline & $V N / r$ & $11 / 9$ & $9 \pi / 9$ & 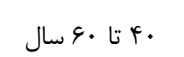 & \\
\hline & VN/9 & $1 T / 9$ & $q F / V$ & بيشتر از •و سال & \\
\hline
\end{tabular}

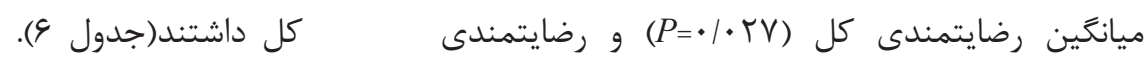

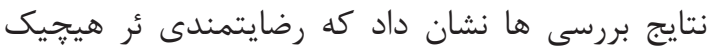

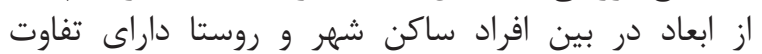

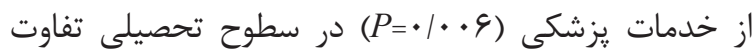

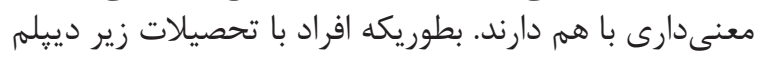

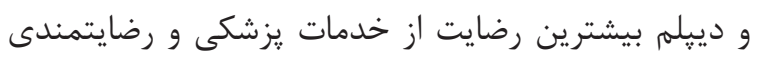

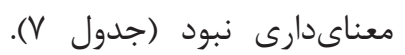

جدول צ: بررسى رضايتمندى و ابعاد آن بر حسب تحصيلات بيماران بسترى در بخش ارولوزى

\begin{tabular}{|c|c|c|c|c|c|}
\hline$P$ & ميانكين از . . & انحراف معيار & ميانكَين & طبقات & ابعاد \\
\hline \multirow{3}{*}{.1 .94} & $1 \cdot / 9$ & $q / f$ & $r \cdot 10$ & بي سواد & \multirow{3}{*}{ خدمات يرستارى } \\
\hline & $\Lambda \kappa / 1$ & 91. & $41 / 9$ & زير دييلم و دييلم & \\
\hline & vq/. & $V / I$ & $\mathrm{rN} /$. & دانشكاهى & \\
\hline \multirow{3}{*}{$.1 . .9$} & $V V / \Lambda$ & $F /$. & $\mid Q / 9$ & بى بواد & \multirow{3}{*}{ خدمات يزشكى } \\
\hline & $\Lambda \Gamma / \Delta$ & $r / q$ & $19 / 0$ & زير دييلم و دييلم & \\
\hline & $9 \mathrm{~V} /$. & $F / T$ & $\mid r / 4$ & دانشكاهى & \\
\hline
\end{tabular}




\begin{tabular}{|c|c|c|c|c|c|}
\hline$P$ & ميانكين از . . & انحراف معيار & ميانكَين & طبقات & ابعاد \\
\hline \multirow{3}{*}{. ATr } & $V \backslash / \Delta$ & $\mathrm{V} / \mathrm{\Lambda}$ & $r \Delta / \Lambda$ & بيسواد & \multirow{3}{*}{ خدمات عمومى } \\
\hline & $V F / \Lambda$ & $V / T^{e}$ & rv/f & زير دييلم و دييلم & \\
\hline & $v \cdot 10$ & $\mathrm{~V} / \mathrm{\Delta}$ & $r \Delta / r$ & دانشكاهى & \\
\hline \multirow{3}{*}{.$/ \cdot r V$} & $v \varepsilon / \Delta$ & 1.19 & $91 / 1$ & بى بـواد & \multirow{3}{*}{ رضايتمندى كل } \\
\hline & $\vee 9 / 9$ & $\mid r / \Lambda$ & $9 \Delta / \Delta$ & زير دييلم و دييلم & \\
\hline & $V T / T$ & $I T / V$ & $\Lambda \& / V$ & دانشَاهى & \\
\hline
\end{tabular}

جدول V. بر رسى رضايتمندى و ابعاد آن بر حسب محل سكونت در بيماران بسترى در بخش ارولوزى

\begin{tabular}{|c|c|c|c|c|c|}
\hline$P$ & ميانگين از . & انحراف معيار & ميانگين & طبقات & ابعاد \\
\hline \multirow{2}{*}{ - IDFT } & $\Lambda \cdot / \cdot$ & $8 / 9$ & $r \cdot 1$ & شهر & \multirow{2}{*}{ خدمات يرستارى } \\
\hline & $\Lambda 1 / V$ & $\Delta / V$ & $f \cdot 19$ & روستا & \\
\hline \multirow{2}{*}{. } & $V V / r$ & $f / r$ & $10 / \Delta$ & شهر & \multirow{2}{*}{ خدمات يزشكى } \\
\hline & $\lambda F /$. & $r / 9$ & 1811 & روستا & \\
\hline \multirow{2}{*}{. / } & $V T / r$ & $\Lambda / r$ & $r g / r$ & شهر & \multirow{2}{*}{ خدمات عمومى } \\
\hline & $V \Delta / \Lambda$ & $\mathrm{V} / \cdot$ & $r V / q$ & روستا & \\
\hline \multirow{2}{*}{.1194} & $V \varepsilon / f$ & $\mid \Delta / 1$ & $91 / 8$ & شهر & \multirow{2}{*}{ رضايتمندى كل } \\
\hline & V9/V & $I T / T$ & $90 / 9$ & روستا & \\
\hline
\end{tabular}

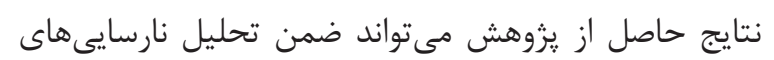

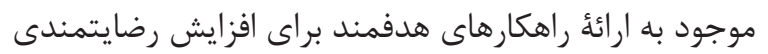

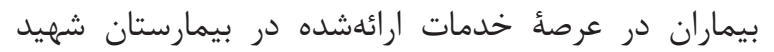

$$
\text { بهشتى همدان منجر شود. }
$$

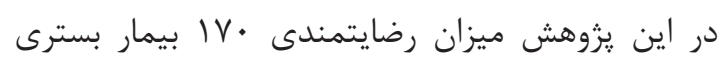

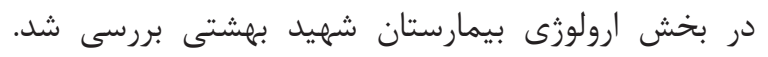

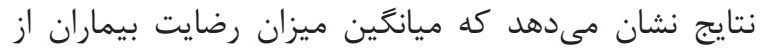

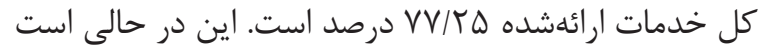

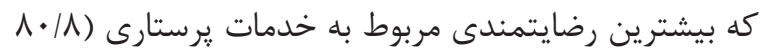

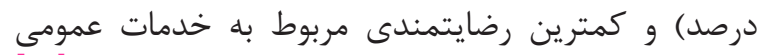

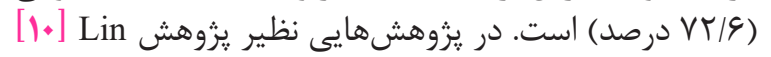

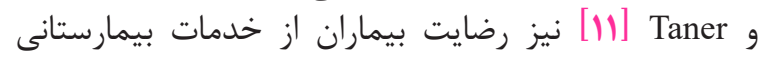

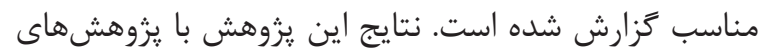
Seidi

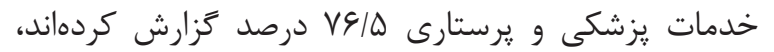

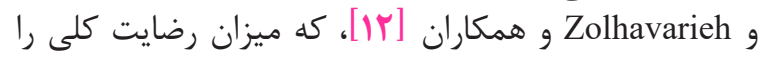

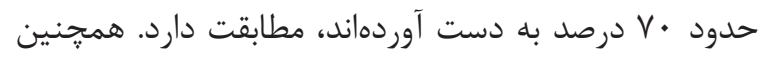
Ebrahimnia

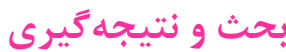

جلب رضايت هرجه بيشتر بيماران ضمن ترغيب آنها به

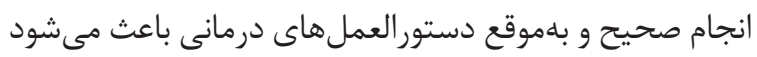

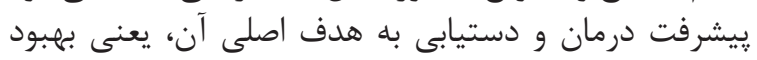

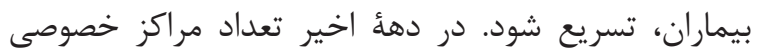

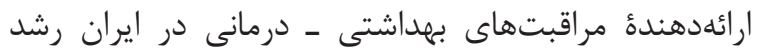

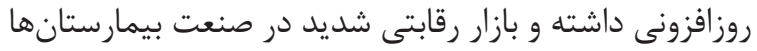

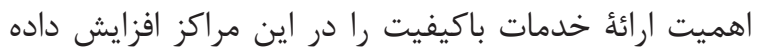

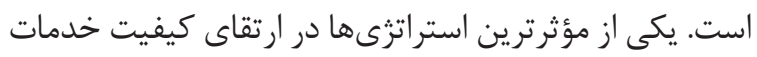

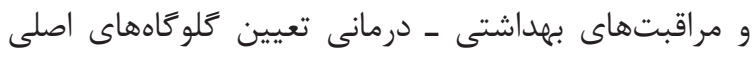

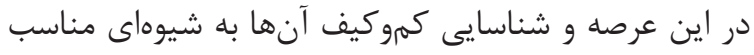

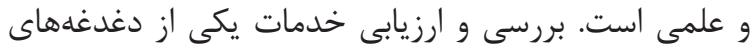

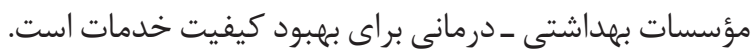

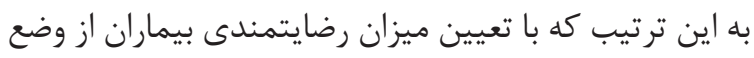

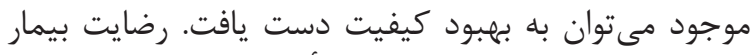

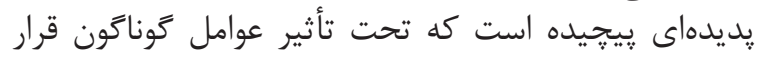

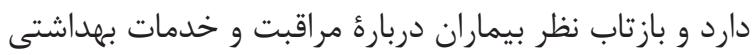

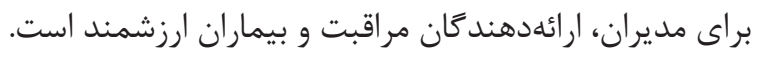


ارزيابى كردهاند. در بيشتر اين يزوهشها بين، بين رضايتمندى،

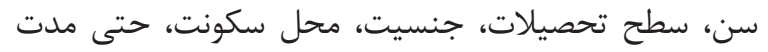

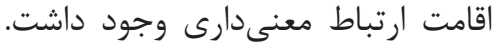

ييشنهاد ميىشود آموزشهاى لازم براى ارتقاى فرهنَ

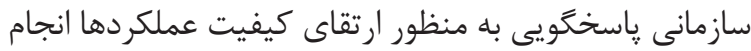

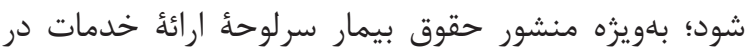

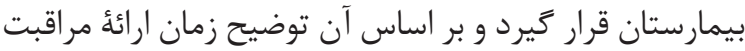

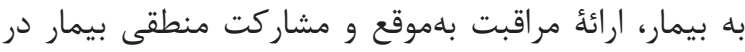

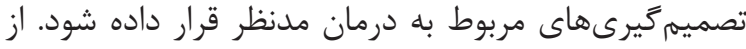

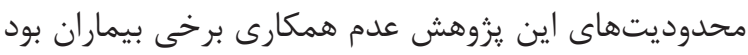
كه با توضيح اهداف طرح تا حدودى برون بروف عرف گرديد.

نتايج حاصل از مطالعه نشان داد ميزان رضايت بيماران از

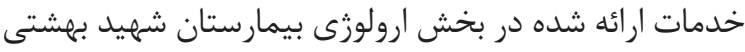

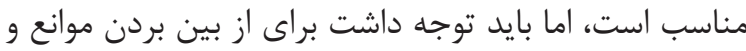

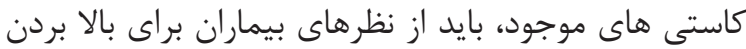

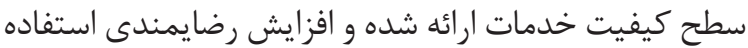

\section{سباسگزן ارى}

نويسند

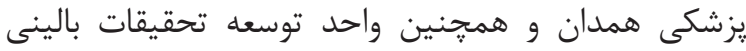

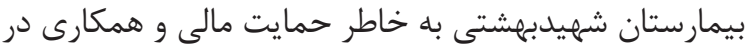

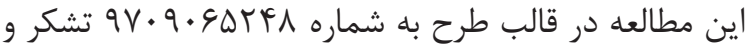
قدردانى مى كنـند. تنعارض در منافع بين نويسند كان هيج گَونه تعارضى در منافع وجود ندارد.
را در بيمارستانهاى نظامى بررسى كردهاند، رضايت بالاتر و

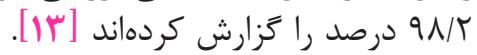

در بخش خدمات يرستارى بيشترين رضايتمندى مربوط

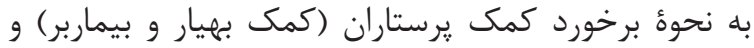

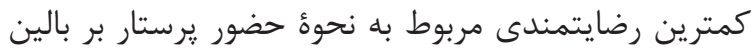

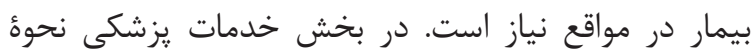

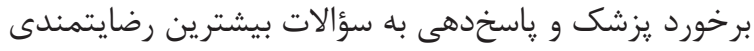

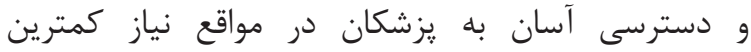

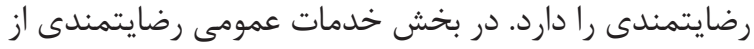

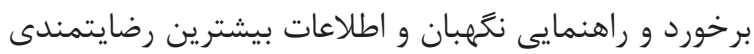
و كيفيت غذا كمترين رضايتمندى رانم ران دارد.

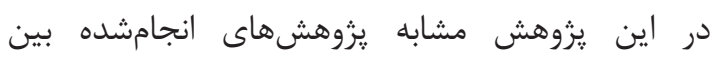

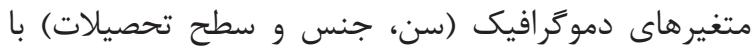

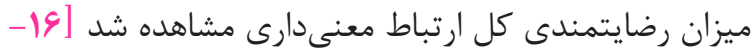

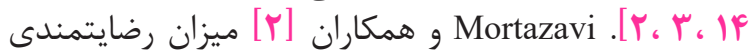

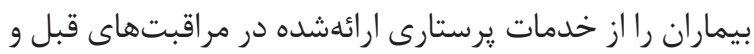

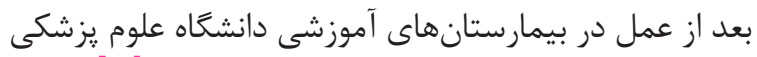

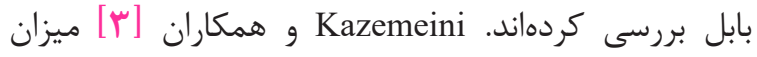

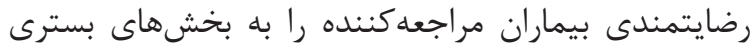

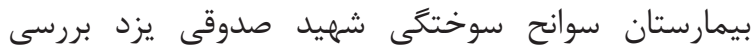

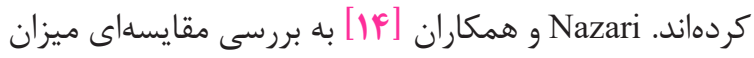

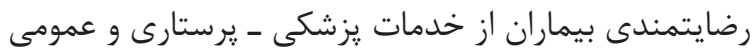

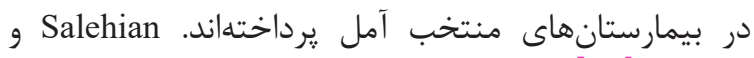

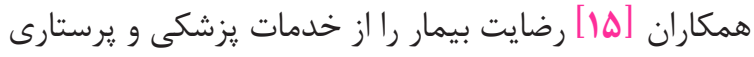

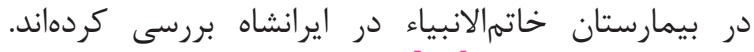
Joolaee

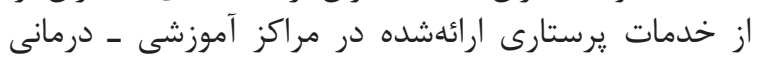




\section{References}

1. Jabraeily M, Rahimi B, Khodayari R, Goli Farhodi G, Mohamadi A. Assessment of inpatient satisfaction with quality services in training centers of Urmia University of Medical Sciences with the servequal model. Health Inf Manage. 2012;7(2):19-24.

2. Mortazavi Y, Rabiee O, Rohi Z, Ghomi S. Patient Satisfaction from Pre and Postoperative Nursing Care in Hospitals Affiliated to Babol University of Medical Sciences. Preventive Care in Nursing \& Midwifery Journal. 2013 Sep 15;3(1):38-45.

3. Kazemeini SK, Mohammadi F, Owlia F. Evaluation of satisfication rate of patients admitted to Yazd Shaheed Sadoughi burn hospital in first nine months of the year 2011. TB. 2013;11(4):91-102.

4. Seyedoshohadaee M, Mohammadi H, Seyedfatemi N, Mehran A. Relationship between the circadian types and nurses' caring behaviours. Koomesh. 2015 Apr 15;16(3):389-96.

5. Neishabory M, Raeisdana N, Ghorbani R, Sadeghi T. Nurses' and patients' viewpoints regarding quality of nursing care in the teaching hospitals of Semnan University of Medical Sciences, 2009. Koomesh. 2011 Jan 15;12(2):134-43.

6. Bahri N, Arabnejad BA, Bahri N, Eshaghi F, Fathi Najafi T, Larki M. Objective Structured Clinical Evaluation for assessment of the quality of practice of health practitioners during preconception, prenatal and postnatal cares. koomesh Journal. 2015;17(1):45-53

7. Mohebbifar R, Barikani A, Hasani H. Measuring hospital Service Quality Gap from the viewpoint of inpatients in educational hospitals of Qazvin University of Medical Sciences (2012-13) Journal of Hospital. 2015;14(1):97-104

8. Sedighi J, Farzadi F, Maftoon F, Nooraee M, Zafarghandi MR, Harirchi E. Performance assessment Model Design for Medical Science University. Payesh. Journal of Health Sciences Research Institute, University Jihad. 2005;4(4):297-85.
9. Sina K, Babai Shibabandani M, Nadi Ghara A. Factors influencing the inpatients' satisfaction based on the Servqual model. Journal of Mazandaran University of Medical Sciences. 2015 Feb 15;24(121):299-308.

10. .Lin DJ, Li YH, Pai JY, Sheu C, Glen R, Chou MJ, Lee CY. Chronic kidney-disease screening service quality: questionnaire survey research evidence from Taichung City. BMC health services research. 2009 Dec;9(1):239.

11. .Taner T, Antony J. Comparing public and private hospital care service quality in Turkey. Leadership in health services. 2006 Apr 1;19(2):1-0.

12. Zolhavarieh SM, Rezaee M, Rassoli P. Evaluation of Satisfaction in Hospitalized Patients in Urology Ward at the Hamedan Medical Sciences University, Shahid Beheshti Hospital during First and Second Half Year of 2013.

13. Ebrahimnia M, Ameriun A, Azizabadi Farahani M, HR KV. Satisfaction rate of hospitalized patients in military hospitals from presented services. Journal Mil Med. 2010 Jul 15;12(2):101-5.

14. .Nazari RB, Amini J, Sharifnia SH, Babaalipour Mouziraji F, Akbari S. A comparative study on patient satisfaction with hospital services in Amol. The Journal of Urmia Nursing and Midwifery Faculty. 2011;9(3):188-95.

15. .Salehian TS, Pirak A. Patients' Satisfaction from Medical and Nursing Services in Khatam Alanbia Hospital in Iranshahr. Jgbfnm. 2010;7(2):33-41.

16. Joolaee S, Hajibabaee F, Jalal EJ, Bahrani N. Assessment of Patient Satisfaction from Nursing Care in Hospitals of Iran University of Medical Sciences. Hayat. 2011 Mar $1 ; 17(1)$.

rV 